\title{
'SO MANY DIFFERENT PEOPLE IN THE SAME DEVICE' RECENT CARIBBEAN BIBLIOGRAPHY
}

\begin{abstract}
Lambros Comitas. The Complete Caribbeana, 1900-1975 (Millwood, New York: KrausThomson Organization Ltd., 1977). 4 vols. Vol. I, 1xxiii, 647 pp.; Vol. II, x1, 700 pp.; Vol III, xi, 672 pp.; Vol. IV, xi, 162 pp. (\$179.00)

John F. SZWED and Roger D. Ábrahams (with Robert Baron, Linda Rabben, Richard Raichelson, Beverly Robinson, Robert Ulle and Richard Wright). Afro-American Folk Culture: an Annotated Bibliography of Materials from North, Central and South America and the West Indies. (Publications of the American Folklore Society, Bibliographical and Special Series, Volumes 31-32. Philadelphia: Institute for the Study of Human Issues, 1978), 2 vols, Vol. I, xvii, 467 pp.; Vol. II, viii, 405 pp. (\$48.00)

In Cat's Cradle, Vonnegut has his mad Calypsonian sing: '...And a Chinese Dentist/ And a British Queen/ All fit together in the same machine/ Nice, nice, very nice $[3 \times] /$ So many different people/ In the same device.' The multi-ethnic, multi-lingual, immensely varied islanders of the Caribbean share a broad colonial experience which has placed them, ultimately, in the same general device. Research scholars of the region have for long struggled with the paradox stemming from this diversity - that "precisely what makes the region attractive for comparative study also makes it very difficult to comprehend' (MINTZ 1978:371).* The publication in 1968 of Comitas' one-volume Caribbeana was, therefore, a major event in Caribbean scholarship. The appearance a decade later of his four-volume Complete Caribbeana marks a still-greater accomplishment, and one for which we all should be deeply appreciative.
\end{abstract}

* My comments on the Comitas volumes have inevitably been influenced by SiD MINTZ' erudite and witty review (1978), which I just read. 
The total work runs well over 2200 pages and includes more than 17,000 individual references (all of which, except certain dissertations, were personally examinded by COMITAS and his team). Like its slimmer predecessor, the work is neatly divided into topical chapters, now organized within the first three volumes - I People, II Institutions, III Resources. The 63 topical chapters are further imbedded in nine thematic sections: Introduction to the Caribbean (including such chapters as Bibliographical and Archival Resources; Travel and Description), The Past (including, e.g., Archaeology and Ethnohistory; Slavery and Emancipation), The People (e.g., Socialization, Family and Kinship; Population Segments: East Indians; West Indians Abroad), Elements of Culture (e.g., Ethnic and National Identity; Language and Linguistics), Health Education and Welfare (e.g., Folk Medicine; Housing and Architecture), Political Issues (e.g., Politics and Government; Post-Colonial Issues), Socio-Economic Institutions (e.g., Agricultural Economics; The Fishing Industry), the Environment and Human Geography (e.g., Geology and Land Forms; Weather and Oceanography), and Soils, Crops and Livestock (e.g., Coffee, Cacao, Tobacco and Root Crops; Silviculture and Lumbering).

Technically, the work is first-rate - clear layout and design, crisp typography, and handsome binding. I found but a few typos and only occasional translation infelicities (all non-English-language titles are given also in English translation). The bibliographical conventions and apparatus are clearly laid out and easy to learn, and there is excellent cross-referencing among chapters. The body of the work is preceded by an enormous list of periodical abbreviations covering some 1500 journals and newspapers, as well as by codes to libraries and to geographical areas. Each full bibliographical entry in the text includes both a geographical identification and a library location. (Unfortunately, as these latter locations are but one per entry, they cannot be used to check at a glance the local availability of particular items; such a listing, systematically including at least one Caribbean location and one in Europe would have nicely complemented the U.S. listing provided - but, as MINTZ remarks (1978:373), 'one can hardly expect Comitas to do one's research for one!') The fourth and final volume consists entirely of two comprehensive and extremely valuable indices, one organized 
by author, the other by geographical area. Thanks to the latter, one can quickly and almost effortlessly locate, for example, studies of agriculture in Grenada, folk medicine in Belize, or any other specialized topic that might strike a researcher's fancy.

The Complete Caribbeana has broadened the geographical range of its earlier incarnation, adding the Bahamas and Bermuda. As it stands, its coverage includes 'those mainland and insular possessions or former possessions of Great Britain, France, the Netherlands, and the United States in the Caribbean region... [including] Surinam[e], French Guiana, and Guyana in South America, Belize in Central America, the Bahamas and Bermuda... and the scores of inhabited islands of the Antillian archipelago except Haiti, Cuba, Puerto Rico and the Dominican Republic' [my italics] (ComITAs, p. xi). Given what he has accomplished, ComITAS can hardly be faulted for the omission of three of the Greater Antilles - the task might simply have been too great, and might have delayed publication inordinately. Yet, for those researchers who work on these areas, COMITAS' statements that 'a considerable bibliography already exists for these important territories' and that 'the geographical units ultimately selected for coverage form a distinctive and meaningful whole' may seem somewhat lame. I, at least, have never been overly impressed with the state of Haitian or Dominican bibliography (though LOWENTHAL \& WOODSON 1974 is one notable exception), nor do I see how the Cuban, Puerto Rican or Haitian historical experience is any less a part of the general Caribbean 'device' than is that of Jamaica. There are minor geographical exclusions from the Caribbean whole as well, e.g. the islands of San Andrés and Providencia, which in cultural terms are quite West Indian, though politically part of Colombia. Their exclusion from the bibliography eliminates PETER WILSON's Oscar as well as several other works of relevance to Caribbean anthropologists.

The reviewer of a bibliography - particularly if he is himself a sometime bibliographer - may perhaps be excused a small self-indulgence. In the present case, I have allowed myself to 'try out' the Comitas work on home turf, as it were, by examining his chapter on 'Bush Negroes' or Maroons. A few rough counts tell part of the story: COMITAS's Suriname Maroon references number about 181 (five of which in fact have nothing to do with Maroons); of these, 
10 - almost all of them medical references - do not appear (through my own negligence) in my published bibliography on the subject (1976). But my bibliography does include approximately 1000 references on Suriname Maroons, published between 1900 and 1975, that are missing from CoMITAs's work. These omissions do not seem to be explicable in any systematic way. They range from several of HERSKOVITS' pioneering papers ('On the provenience of the Portuguese in Saramacca Tongo,' 'Bush Negro Art,') to $64 \%$ (27 out of 42) of the relevant works of L.C. VAN PANHUYS, and a surprising $90 \%$ (29 out of 33) of the relevant writings of W.F. VAN LIER. And the work of modern authorities, such as H.U.E. THODEN VAN VELZEN, is also covered sporadically. Since many of the omitted items appeared in journals that are elsewhere cited by Comitas (e.g., De West-Indische Gids), it appears that complete runs of journals were not reviewed systematically, certainly a methodological shortcoming in the compilation of a work as ambitious as this one. Of course, this chapter of the bibliography might be expected to be one of its weakest, in that a significant portion of the literature is in Dutch. Nevertheless, the total percentage of coverage $-15 \%$ (176 of 1200 , probably a 'high' estimate since my own bibliography is certainly incomplete) - calls into question MINTZ' generous expression of 'more than reasonable confidence that these volumes make available in convenient form a very substantial proportion perhaps something like $75-80 \%$ - of what is available on the topic of interest, for the societies covered' (1978:372).

But enough nitpicking. No significant bibliography can pretend to completeness, and the fact remains that CoMITAS's Complete $\mathrm{Ca}$ ribbeana is far and away the finest research tool ever offered Caribbeanist scholars. It will stand as a landmark publication, unchallenged in breadth and depth, for a very long time to come. COMITAS and his coworkers at the Research Institute for the Study of Man have made scholarship and teaching significantly easier for each of us, and for this we are all very much in their debt.

The two-volume SzWED/ABRAHAMS bibliography is at once a more limited and modest work and one that is, in my view, more intellectually challenging. Focusing exclusively on 'the expressive 
and symbolic aspects of the lives of ordinary people' throughout Afro-America, it is intended to be used 'in conjunction with those other bibliographies which are more concerned with the history, economics and social organization of black people' (xiii-xiv). It is, as the authors state in their brief but excellent introduction, 'a bibliography with a thesis... [written] because of our frustrations arising from the unwillingness of both the academic community and the general public to recognize that a huge body of material exists on Afro-American traditions and cultural expressions' (ix).

The two volumes are set in clear, offset typography. I was alarmed to find a misspelling of the author's name in the very first entry of the bibliography but, on further reading, found the overall technical standards adequate for a work of this kind. The majority of bibliographical entries are followed by a 1-2 sentence descriptive annotation, often pointing to an aspect of the work that might otherwise not be at all apparent to the reader from the title alone. For example, an obscure eighteenth-century journal [NA 2578] turns out to include a description of 'the barrafou, an African xylophone played by a slave near Fredericksburg', and other such scattered bits of fascinating information are signalled throughout the annotations. Each volume is followed by a General Index and a [geographical] Locale Index; no Author Index is provided, but this is only a minor inconvenience because of the relative lack of internal subdivision in the text itself. The overall organization of the work is geographical: following listings of Bibliographical and General works, the bulk of Vol. I is devoted to a single alphabetical listing of North American materials, while Vol. II is sub-divided into 26 geographical sections (e.g. Dominican Republic, Belize, Brazil, Uruguay). The intent throughout is to facilitate cross-cultural comparison and the examination of similarities and differences from one Afro-American setting to another, as well as through time. This last point is important, for - along with the truly Hemispheric approach - it is the major conceptual difference between this work and that of COMITAS. While COMITAS treats only post1900 publications, SZWED \& ABRAHAMS take on the full span of the Afro-American historical experience.

Dissertations and other unpublished materials are not included 
in this bibliography, in contrast to that of COMITAS, but many literary works, record liners and other less-usual resources for scholarship are listed. In some ways, this work - in spite of its broad geographical and temporal scope, and its total of 6,426 entries - is more an exploratory than a definitive bibliography. But it is nevertheless guaranteed to delight all serious Afro-Americanists. The extensive index runs from 'Africa: questions of antecedents and influences' to 'Zydeco' (Black Cajun music from Louisiana), with stops in between for such topics as 'Afro-American contacts with American Indians,' 'African "'nations,', 'Dance, dance music, and songs,' 'Dirt Eating,' 'Dreams,' 'Food and cooking.' 'Lullabies,' 'Medicine,' 'Pottery,' 'Proverbs and proverbial expression,' 'Ragtime,' 'Religious rites and services,' 'Rent parties,' 'Slang, argot and jargon,' 'Stick fighting,' 'Secret systems of writing,' and a host of others.

With its uniquely pan-Afro-American perspective, the Szwed/ Abrahams bibliography is a veritable treasure-trove for researchers. Along with the Comitas volumes, it will play a major catalytic role in encouraging new generations of scholars to build on the insights of their predecessors as they move toward a fuller understanding of the complex development of culture and society in the Americas.

\section{REFERENCES}

Comitas, Lambros, 1968. Caribbeana 1900-1965. A topical bibliography. Seattle and London: University of Washington Press.

Lowenthal, Ira P. \& Woodson, Drexel G. (rédacteurs), 1974. Catalogue de la collection Mangonès, Pétionville, Haiti. New Haven: Antilles Research Program, Yale University.

MINTZ, Sidney W., 1978. Review article: Comitas, The Complete Caribbeana. Revista Interamericana $7: 371-374$.

PRICE, RICHARD, 1976. The Guiana Maroons: a historical and bibliographical introduction. Baltimore and London: The Johns Hopkins University Press.

RICHARD PRICE, Department of

Anthropology, The Johns Hopkins

University, Baltimore, Maryland 21218. 